\title{
Chinese Consensus on Antiviral Treatment of Chronic Hepatits B Patients with Nucleos(t)ide Analogues
}

Professional Staff Committee of Chinese Consensus on Treatment of Chronic Hepatits B Patients with Nucleos(t)ide Analogues

A ntiviral treatment is the main method for chronic hepatitis B (CHB). After antiviral treatment, some patients may obtain satisfactory therapeutic effect, but some patients still occurred primary non-response, suboptimal response, even resistance to nucleos(t)ide analogues or relapse, which are becoming the key problems confusing the clinical staffs. Thus, in January 2013, editorial department of Chinese Journal of Experimental and Clinical Infectious Diseases (Electronic Edition), Chinese Journal of Liver Diseases (Electronic Edition) and Infection International (Electronic Edition) organized an expert committee to form an expert consensus on antiviral treatment of CHB patients with nucleos(t)ide analogues. In this consensus, only primary non-response, suboptimal response and relapse were involved, and the management of resistance could be refered to the consensus on management of drug resistance to nucleos(t)ide analogues in patients with CHB. ${ }^{1}$ The consensus publication promoted and standarized treatment of CHB patients with nucleos $(\mathrm{t})$ ide analogues. Clinical evidence of treatment of CHB patients with nucleos(t)ide analogues is increasing. The formulation of this consensus is according to the principles of evidence-based medicine, but large number of clinical studies of combination therapy is still in progress. This consensus can not fully answered the problems encountered in antiviral the treatment of CHB patients with nucleos(t)ide analogues. With the progress of clinical practice, the evidence is accumulating continuous and professional staff committees will update the consensus. The evidence gradings in the consensus are listed in Table 1.

Correspondence: Jun Cheng, Institute of Infectious Diseases, Beijing Ditan Hospital, Capital Medical University; 8 East Jingshun Street, Chaoyang District, Beijing 100015, China

Tel: +86-10-84322006; Fax: +86-10-84397196; E-mail: jun.cheng. ditan@gmail.com

\section{TREATMENT OF PRIMARY NON-RESPONSE PATIENTS WITH CHRONIC HEPATITIS B}

\section{Definition of primary non-response}

Two descriptions for non-response to nucleos $(t)$ ide analogues are defined: primary treatment failure and primary non-response. Furthermore, different guidelines showed obviously different definitions for this term (Table 2), leading to a puzzle in clinical practice. Actually, both "primary treatment failure" and "primary non-response" describe the same condition. So we suggest a standard and unified term to definite these conditions. Experts committee recommended that non-response is defined as less than $1 \log _{10} \mathrm{IU} / \mathrm{ml}$ decrease in HBV DNA level from baseline at week 12 of therapy in naïve and compliant patients who fulfilled the indications for antiviral therapy.

Evaluation of $\mathrm{CHB}$ patients with primary non-response Primary non-response need to be assessed in clinical practice as follows:

\section{Patients}

Most importantly, indications for antiviral treatment should be strictly followed. Moreover, all patients should be checked for compliance including dose, administration route, strict frequency and enough treatment duration or so. All patients should be informed of possible risks after random treatment cessation in order to obtain an improved treatmet compliance.

\section{Drugs}

Many studies showed that high virus load is usually associated with lower rates of virological response (undetectable HBV DNA) under monotherapy of adefovir dipivoxil (ADV), lamivudine (LAM) or telbivudine (LdT). ${ }^{6}$ Furthermore, adefovir dipivoxil can engender higher rates of primary non-response $(10 \%$ 
Table 1. Levels of evidence criteria

\begin{tabular}{ll}
\hline Levels of evidence & Criterias \\
\hline I & At least one well-designed randomized, controlled trial \\
II & Well-designed cohort or case-controlled trial \\
III & Serial case or single case report or defective-designed clinical trials \\
IV & Opinions of anthoritative experts based on clinical experience, descriptive study or meeting reports \\
\hline
\end{tabular}

Table 2. Definitions of primary non-response for antiviral therapy in patients with chronic hepatitis B

\begin{tabular}{ll}
\hline Guidelines & Definitions \\
\hline AASLD $(2009)^{2}$ & $\begin{array}{l}\text { Primary non-response: less than } 2 \log _{10} \mathrm{IU} / \mathrm{ml} \text { decrease in HBV DNA level from baseline at } 24 \text { weeks } \\
\text { of oral nucleoside/nucleotide analogues therapy, for oral nucleos(t)ide analogues therapy only } \\
\text { Primary treatment failure: less than } 2 \log _{10} \mathrm{IU} / \mathrm{ml} \text { decrease in HBV DNA level from baseline at } 6 \\
\text { months of nucleos(t)ide analogues therapy }\end{array}$ \\
APASL (2012) & $\begin{array}{l}\text { Primary treatment failure: less than } 1 \log _{10} \mathrm{IU} / \mathrm{ml} \text { decrease in HBV DNA level from baseline at } 12 \\
\text { weeks of antiviral therapy with oral drugs }\end{array}$ \\
PASL (2012) & $\begin{array}{l}{ }^{5} \\
\text { Primary non-response: less than } 1 \log _{10} \mathrm{IU} / \mathrm{ml} \text { decrease in HBV DNA level from baseline at } 12 \text { weeks } \\
\text { of antiviral therapy, for both nucleos }(\mathrm{t}) \text { ide analogues and IFN } \alpha \text { therapy }\end{array}$ \\
\hline
\end{tabular}

Notes: AASLD, American Association For the Study of Liver Diseases; CMA, Chinese Medical Association; APASL, Asia Pacific Association for the Study of Liver Research; EASL, European Association for the Study of the Liver.

- 20\%) than entecavir (ETV) and tenofovir dipivoxil (TDF).

\section{Viruses}

Primary non-response may be associated with the dynamic change of HBV quasispecies and the drugresisitant mutations of $\mathrm{HBV}^{7}$ Most researchers consider that if the heterology of viral quasispecies is obvious, the strains composing of viral quasispecies will be so complicated that HBV will adapt to the environment better, leading to more difficulty in antiviral therapy. ${ }^{8-12}$

\section{Antiviral therapy of primary non-response patients}

The correct choice of a first-line potent therapy to achieve sustained long-term suppression of viral replication provides the best chance of preventing treatment failure. With the advent of more potent antiviral drugs, such as TDF and ETV, this phenomenon, often seen with ADV, is now less frequent. When a primary nonresponse is identified, antiviral treatment should be modified to prevent disease progression and subsequent risk of emergence of drug-resistant mutants. According to the roadmap of CHB treatment, ${ }^{13-15}$ the week-12 time point on therapy is important to determine the antiviral activity of the treatment regimen and assess treatment adherence. ${ }^{16-18}$

\section{Patients with suboptimal response to LAM/LdT}

Previous studies showed ADV add-on therapy for these patients may improve virologcal response and decrease drug resistance risk. ${ }^{19,20}$ Other study showed TDF add-on therapy may improve virological response in primary non-response patients. Based on previous studies, it is recommended that patients with primary non-response to LAM/LdT should take ADV/TDF add- on therapy. Switch to TDF can also be considered. But switch to ETV is not recommended, due to its crossresistance site with $\mathrm{LAM} / \mathrm{LdT}^{21}$

\section{Patients with primary non-response to ADV}

Studies showed add-on therapy of LAM/LdT for ADV primary non-response patients may improve virological response. ${ }^{18}$ It is reported that ADV primary non-response patients took ETV switch-to therapy may also improve virological response. ${ }^{22}$ Based on previous studies, it is recommended that patients with primary non-response to ADV should take ETV, LdT or LAM add-on therapy. Switching to TDF or ETV can also be considered.

\section{Patients with primary non-response to ETV/TDF}

A small clinical trial showed TDF swith-to therapy for these patients with primary non-response to ETV may improve virologcal response. ${ }^{23}$ A study in South Korea suggested that add-on ADV for ETV primary non-response patients may improve virological response. ${ }^{18}$ Study showed that for HBeAg positive patients with baseline HBV DNA $\geqslant 8 \log _{10} \mathrm{IU} / \mathrm{ml}$, who took ETV and TDF combination therapy had higher virological response rate than those who took ETV mono-therapy. ${ }^{24}$ Based on previous studies, it is recommended that patients with baseline HBV DNA $\geqslant 8 \log _{10} \mathrm{IU} / \mathrm{ml}$ should take add-on therapy of agents without cross resistance. The rate of primary nonresponse to TDF is low and relevant data is limited. Add-on therapy of ETV, LdT, LAM still need further study.

Patients with primary non-response to NUCs may also consider (Peg-) IFN add-on or switch- 
to therapy. After 12 weeks treatment, HBV DNA, HBeAg and HBsAg levels should be detected, and the treatment strategy should be adjusted according to the results. Individualized therapy is recommended in these patients and side-effects should be monitored closely. Combination of LdT and IFN $\alpha$ should be avoided.

\section{Recommendations}

Primary non-response is defined as less than $1 \log _{10}$ $\mathrm{IU} / \mathrm{ml}$ decrease in HBV DNA level from baseline at 12 weeks of therapy in naïve and compliant patients who fulfil the indications for antiviral therapy. When a primary nonresponse is identified, antiviral treatment should be modified to prevent disease progression and subsequent risk of emergence of populations of drugresistant mutants.

Patients with primary non-response to LAM/LdT should take ADV ( II )/TDF ( II ) add-on therapy. Switch to TDF ( II ) can also be considered. But switch to ETV is not recommended due to its cross-resistance site with LAM/LdT ( II ).

Patients with primary non-response to ADV should take ETV (III), LdT ( II ) or LAM ( II ) add-on therapy. Switch to TDF ( II) or ETV ( II ) can also be considered.

Patients with primary non-response to ETV could switch to TDF ( II ) or add-on ADV (III). Patients with baseline HBV DNA $\geqslant 8 \log _{10} \mathrm{IU} / \mathrm{ml}$ and primary nonresponse to ETV should take add-on therapy of agents without cross resistance (III).

Patients with primary non-response to NUCs may also consider (Peg) IFN add-on or switchto therapy (II). After 12 weeks treatment, HBV DNA, HBeAg and HBsAg levels should be detected, and the treatment strategy should be adjusted according to the results. Combination of LdT and IFN $\alpha$ should be avoided.

\section{TREATMENT OF SUBOPTIMAL RESPONSE CHRONIC HEPATITIS B}

\section{Definition of suboptimal responses}

Description of suboptimal response to NUCs in previous guidelines are shown in Table 3. In this consensus, experts committee recommended the definition of suboptimal response as a decrease in HBV DNA of more than $2 \log _{10} \mathrm{IU} / \mathrm{ml}$, but HBV DNA detectable with sensitive real-time PCR assay after at least 24 weeks of NUCs therapy in compliant patients.

\section{Evaluation of CHB patients with HBV DNA detectable after 24 weeks of NUCs therapy}

Patients with HBV DNA detectable after 24 weeks of NUCs therapy should be evaluated thoroughly as below:

a. Initial indication of antiviral therapy: for some patients who started antiviral therapy in immune tolerance phase, antiviral therapy should be ceased with close monitoring.

b. Previous antiviral therapy: for patients who had been treated with NUCs, further antiviral treatment should be individualized according to patients' previous treatment agents, duration and virological response.

c. Compliance to antiviral therapy: for all patients with HBV DNA detectable after 24 weeks of NUCs therapy, compliance should be evaluated closely. Close monitoring is required in patients with poor compliance. HBV resistance detection should be considered in some patients since irregular drug application may promote HBV resistance to NUCs.

d. HBV resistance to NUCs: For patients with HBV DNA detectable after 24 weeks of NUCs treatment, especially in patients with virological breakthrough, HBV NUCs resistance should be evaluated. For patients with clear genetic resistance to certain NUCs, antiviral therapy should be adjusted (HBV resistance management consensus ). ${ }^{1}$

Initial indication, previous antiviral therapy, compliance and drug resistance should be evaluated closely before patients were defined as suboptimal virological response.

\section{Antiviral therapy of suboptimal response patients Patients with suboptimal response to LAM/LdT} Patients with suboptimal response to LAM/LdT after 24 weeks therapy have higher risk to develop drug resistance. Previous several perspective, randomized and controlled studies showed ADV add-on therapy for these patients may improve virological response and decrease drug resistance risk. ${ }^{19,26}$ One European multicentered cohort study showed TDF add-on therapy may improve virological response in LdT suboptimal response patients. ${ }^{27}$ Based on previous studies, it is recommended that patients with suboptimal response to LAM/LdT should take ADV/TDF add-on therapy. Switch to TDF, ETV + ADV or ETV + TDF can also be considered.

\section{Patients with suboptimal response to $A D V$}

ADV is a less potent agent for HBV and long-term use of ADV may also induce drug resistance in some patients. Patients with suboptimal response to ADV 
after 24 weeks therapy should consider regimen adjustment. Chen et al reported a perspective and controlled study to evaluate 12 months add-on therapy of LAM/LdT for ADV suboptimal response patients. ${ }^{28}$ Results showed that LAM and LdT add-on therapy may both improve virological response for these patients. But LdT add-on group had a higher rate of $\mathrm{HBeAg}$ seroconversion than LAM add-on group. Levrero et al reported that patients who occured ADV suboptimal response and swithed to TDF may also improve virological response $\mathrm{e}^{29}$. Based on previous studies, it is recommended that patients with suboptimal response to ADV should take ETV, LdT or LAM add-on therapy. Switch to TDF or ETV can also be considered.

\section{Patients with suboptimal response to ETV/TDF}

ETV and TDF are potent agents for HBV and have high genetic barrier. Global registration studies showed that most patients who took ETV/TDF and did not achieve HBV DNA undetectable at week 24, can get complete virological response if they continued single agent therapy. ${ }^{30,31}$ Lok et al showed for HBeAg positive patients with baseline HBV DNA $\geqslant 8 \log _{10} \mathrm{IU} / \mathrm{ml}$, those who took ETV and TDF combination therapy had higher virological response rate than those who took ETV mono-therapy. ${ }^{24}$ Based on previous studies, it is recommended that patients with baseline HBV DNA $\geqslant$ $8 \log _{10} \mathrm{IU} / \mathrm{ml}$ and suboptimal response to ETV/TDF at week 24 should take add-on therapy of agents without cross-resistance. Patients with baseline HBV DNA < $8 \log _{10} \mathrm{IU} / \mathrm{ml}$ and suboptimal response to ETV/TDF at week 24 should continue single agent treatment and evaluate virological response at week 48.

IFN treatment for patients with suboptimal response to NUCs

Patients with suboptimal therapy to NUCs may also consider (Peg-) IFN $\alpha$ add-on or switch-to treatment. Individualized therapy is recommended in these patients and side-effects should be monitored closely. Combination of LdT and IFN $\alpha$ should be avoided.

\section{Recommendation}

Suboptimal virological response is defined as a decrease in HBV DNA of more than $2 \log _{10} \mathrm{IU} / \mathrm{ml}$, but HBV DNA detectable with sensitive real-time PCR assay after treatment for at least 24 weeks in compliant patients.

Initial indication, previous antiviral therapy, compliance and drug resistance should be evaluated in patients with HBV DNA detectable after 24 weeks of NUCs therapy.

Patients with suboptimal response to LAM/LdT should take ADV ( I )/TDF ( II ) add-on therapy. Switch to TDF (III), ETV + ADV (IV) or ETV + TDF (IV) can also be considered.

Patients with suboptimal response to ADV should take ETV (III), LdT ( II ) or LAM ( II ) add-on therapy. Switch to TDF (II) or ETV (IV) can also be considered.

Patients with baseline HBV DNA $\geqslant 8 \log _{10}$ IU/ $\mathrm{ml}$ and suboptimal response to ETV/TDF at week 24 should take add-on therapy of agents without crossresistance (III). Patients with baseline HBV DNA < $8 \log _{10} \mathrm{IU} / \mathrm{ml}$ and suboptimal response to ETV/TDF at week 24 should continue single agent treatment and evaluate virological response at week 48 ( I ).

Patients with suboptimal therapy to NUCs may also consider (Peg-) IFN add-on or switch-to therapy (IV). Individualized therapy is recommended in these patients and side-effects should be monitored closely. Combination of LdT and IFN should be avoided.

\section{TREATMENT OF RELAPSING CHRONIC HEPATITIS B PATIENTS AFTER ANTIVIRAL TREATMENT}

\section{Definition of chronic hepatitis $B$ relapse}

Definitions of chronic hepatitis B relapse are listed in Table 4.

The definition in this paper is based on a

Table 3. Suboptimal response to NUCs defined in guidelines

\begin{tabular}{|c|c|}
\hline Guideline/Consensus & Definitions \\
\hline Keeffe Roadmap Report $(2007)^{4}$ & $\begin{array}{l}\text { Partial virological response: a decrease in HBV DNA to less than } 2000 \mathrm{IU} / \mathrm{ml} \text { but detectable } \\
\text { after } 24 \text { weeks of therapy. }\end{array}$ \\
\hline $\begin{array}{l}\text { Chinese Expert Recommendation on NUCs } \\
\text { Combination Therapy for CHB }(2011)^{25}\end{array}$ & $\begin{array}{l}\text { Suboptimal response: a decrease in HBV DNA to more than } 2 \log _{10} \text { copies } / \mathrm{ml} \text { but detectable } \\
\text { after certain duration NUCs therapy ( } 24 \text { weeks of LAM, LdT and ETV; } 48 \text { weeks of ETV, } \\
\text { LLD of HBV DNA defined as } 1000 \text { copies } / \mathrm{ml}) \text {. }\end{array}$ \\
\hline APASL CHB guideline $(2012)^{4}$ & $\begin{array}{l}\text { Suboptimal virological response: serum HBV DNA still detectable at } 24 \text { weeks of a oral } \\
\text { antiviral therapy in adherent patient }\end{array}$ \\
\hline EASL CHB guideline $(2012)^{5}$ & $\begin{array}{l}\text { Partial virological response: a decrease in HBV DNA of more than } 1 \log _{10} \mathrm{IU} / \mathrm{ml} \text { but } \\
\text { detectable HBV DNA after at least } 6 \text { months of therapy in compliant patients }\end{array}$ \\
\hline
\end{tabular}

Notes: APASL, Asia Pacific Association for the Study of Liver Research; EASL, European Association for the Study of the Liver. 
Table 4. Definitions of chronic hepatitis $B$ relapse in guidelines

\begin{tabular}{|c|c|}
\hline Guidelines & Definitions \\
\hline $\operatorname{AASLD}(2009)^{2}$ & $\begin{array}{l}\text { The results of twice detections of HBV DNA with an interval of at least } 4 \text { weeks shall be }>1 \log _{10} \mathrm{IU} / \mathrm{ml} \\
\text { higher than the lowest endpoint of treatment. }\end{array}$ \\
\hline CMA $(2010)^{3}$ & $\begin{array}{l}\text { Virus response is observed at the end of treatment. However HBV DNA would re-raise or seroconvert with } \\
\text { ALT and AST increase following drug-withdrawal, but the other factors elevating ALT and AST should be } \\
\text { excluded. }\end{array}$ \\
\hline APASL $(2012)^{4}$ & $\begin{array}{l}\text { Virological relapse: serum HBV DNA }>2000 \mathrm{IU} / \mathrm{ml} \text { after drug-withdrawal in patient that obtain viral } \\
\text { response. } \\
\text { Clinical relapse: the serum HBV DNA }>2000 \mathrm{IU} / \mathrm{ml} \text { and ALT }>2 \times \mathrm{ULN} \text { after drug-withdrawal in patient } \\
\text { that obtain viral response. }\end{array}$ \\
\hline
\end{tabular}
Study of Liver Research.

comprehensive consideration of guidelines and practical operability, that is, viral response could be observed at the end of treatment, but HBV DNA levels with an internal of at least 4 weeks after drugwithdrawal raise $>1 \log _{10} \mathrm{IU} / \mathrm{ml}$ than the lowest point of primary treatment endpoint, with or without ALT elevated, and other factors causing ALT elevation should be excluded.

\section{Reasons and types of chronic hepatic $B$ relapse}

Due to a long half-life of HBV cccDNA replication module, it is difficult to completely clear HBV from liver by current antiviral drugs, which lead to higher relapse rate after drug-withdrawal.

Two types of chronic hepatitis B relapse are discussed here: one is for patients who received effective treatment and reached the standard of drugwithdrawal, namely patients with effective treatment and standard of drug-withdrawal. The other is for patients who received effective treatment but did not reach the standard of drug-withdrawal, namely patients with effective treatment and non-standard drug withdrawal.

The standard of drug-withdrawal for $\mathrm{HBeAg}$ positive patients in guideline of Chinese CHB Prevention and Treatment is: if HBV DNA undetectable, ALT normalization and $\mathrm{HBeAg}$ seroconversion remained followed by a consolidation therapy for at least 1 year (at least 2 reviews with an interval of 6 months), with a total course at least 2 years, then drug-withdrawal ( II) could be considered, but longer duration may reduce relapse. For patients with $\mathrm{HBeAg}$ negative, the treatment course should be longer and drug-withdrawal ( II ) could be considered if patients achieving HBV DNA undetectable, ALT normalization followed by a consolidation therapy for at least 1.5 years (at least 3 reviews with an interval of 6 months and a total course treatment of at least 2.5 years. As the relapse rate is high due to drug withdrawal, a duration course should be considered.

\section{Treatment for patients with chronic hepatitis B relapse}

\section{Relapsed patients who received effective primary treatment and reached drug-withdrawal standard}

Generally, primary drugs applied for treatment are recommended. However, several studies showed that relapse could still occur in spite of strict standard of drug-withdrawal, which imply that the retreatment course should be longer. ${ }^{32-36}$ So low-resistance drugs such as ETV and TDF are strongly recommended in long-course treatment, concerning the resistance risk of long-term treatment. ${ }^{37}$ A report showed that 192 $\mathrm{HBe} \mathrm{Ag}$ positive patients with LAM primary treatment could obtain $\mathrm{HBeAg}$ seroconversion quickly with LAM retreatment after drug-withdrawal relapse, which could not maintain for a long time. Another study showed that if patients with viral response to ETV treatment were given sequential LAM treatment, then it was hard to mantain previous response, ${ }^{38}$ which showed CHB patients with relapse after drug-withdrawal should continue or switch to potent low-resistance drugs for long-term treatment (ETV or TDF).

For relapsed patients who reached standard of drugwithdrawal during NUCs primary treatment could also take NUCs combined therapy. A study showed that $53 \mathrm{HBeAg}$ positive CHB patients were given LAM treatment or LAM-ADV combined treatment when they relapsed after drug-withdrawal of LAM primary treatment. ALT normalization, $\mathrm{HBeAg}$ seroconversion and drug-resistance were all better in the combined treatment group than single drug treatment group. So combined treatment is a better option for relapsed patients after drug-withdrawal with single treatment. ${ }^{39}$ There should be no cross-resistance among the drugs applied in the combination therapy.

So far there is still no agreement on potent single treatment or NUCs combined treatment. For relapsed patients with higher viral load (HBV DNA $>1.0 \times 10^{7}$ $\mathrm{IU} / \mathrm{ml}$ ), the combined treatment is recommended. For relapsed patients with viral load $<1.0 \times 10^{7} \mathrm{IU} / \mathrm{ml}$, 
single treatment with potent and low-resistance NUCs could also be applied. HBV DNA should be detected at 24 weeks. An optimized combined treatment should be considered if the response is not optimal (HBV DNA level decreases $<2 \log _{10} \mathrm{IU} / \mathrm{ml}$ compared with the level before treatment).$^{40}$

\section{Relapsed patients with effective treatment but without standard of drug-withdrawal}

Treatment continuing is recommended and the regimen could refer the protocol of relapsed patients after effective treatment with standard of drug-withdrawal. But some evidences showed that although patients receiving LAM treatment did not occur drug-resistance, the long-term resitstance become obviously higher after switching to ETV treatment. So combination with ADV is recommended as early as possible for these cases. ${ }^{40}$

\section{Recommendation}

Definition of chronic HBV relapse: viral response could be observed at the end of treatment, but HBV DNA levels with an internal of at least 4 weeks after drug-withdrawal raise $>1 \log _{10} \mathrm{IU} / \mathrm{ml}$ than the lowest point of primary treatment endpoint, with or without ALT elevated, and other factors causing ALT elevation should be excluded ( II ).

Recommendation for relapsed patients who received effective treatment and reached standard of drugwithdrawal is to continue the primary treatment. However due to the resistance risk of a long-term treatment, it is recommended to choose potent lowresistance drugs (ETV and TDF) for a long-term treatment ( II).

Relapsed patients who reached standard of drugwithdrawal in primary NUCs treatment could receive NUCs combined treatment. Especially the patients with viral load $<1.0 \times 10^{7} \mathrm{IU} / \mathrm{ml}$ could be given potent lowresistance single NUCs treatment, with observation of their viral load at 24th week. If the response is poor (HBV DNA level decrease $<2 \log _{10} \mathrm{IU} / \mathrm{ml}$ than primary treatment), then combined treatment could be considered ( II ).

Relapsed patients who received effective treatment but without standard of drug-withdrawal should be given a retreatment based on the same principles of patients reaching standard of drug-withdrawal (II).

For patients who received LAM treatment without resistance, the long-term resitstance become obviously higher after switching to ETV treatment. So combination with ADV is recommended as early as possible (II).

Relapsed patients who received effective NUCs primary treatment (including those who reaching drug-withdrawal standard or not), could also switch to interferon treatment alone or combined with NUCs (LdT is excluded) (III).

(Drafted by Yan-bin Wang, Hong Zhao and Song Yang)

(Committee of experts: Yong-ping Chen, Jun Cheng, Xuefei Duan, Xiao-guang Dou, Tao Han, Jun Li, $\mathrm{Ke} \mathrm{Li}, \mathrm{Xu} \mathrm{Li}$, Wan-hua Ren, De-ming Tan, Hong Tang, Lei Wang, Maorong Wang, Wen Xie, Hui-chun Xing, Xin-xin Zhang, Zhen Zhen and Xia-qiu Zhou)

\section{REFERENCES}

1. Committee of Experts on Drug Resistance of Hepatitis B Virus. Updation of experts consensus on drug resistance of hepatitis B virus in 2009. Zhonghua Shi Yan He Lin Chuang Gan Ran Bing Za Zhi (Chin) 2009; 3(1):72-79.

2. Experts attending the discussion on hepatitis B virus drug resistance. Drug resistance to nucleoside and nucleotide analogs in chronic hepatitis B and its management. Zhonghua Shi Yan He Lin Chuang Gan Ran Bing Za Zhi (Chin) 2012; 6(6):643-650.

3. Lok AS, McMahon BJ. Chronic hepatitis B: update 2009. Hepatology 2009; 50(3):661-662.

4. Chinese Society of Hepatology and Chinese Society of Infectious Diseases, Chinese Medical Association. Guideline of prevention and treatment for chronic hepatitis B (2010 version). Zhongguo Gan Zang Bing Za Zhi (Chin) 2011; 3(1):40-56.

5. Liaw YF, Kao JH, Piratvisuth T, Chan LY, Chien RN, Liu CJ, et al. Asian-Pacific consensus statement on the management of chronic hepatitis B: a 2012 update. Hepatol Int 2012; 6(3):531-561.

6. EASL clinical practice guidelines: Management of chronic hepatitis B virus infection. European Association For The Study of The Liver. J Hepatol 2012; 57(1):167-185.

7. Zoulim F, Perrillo R. Hepatitis B: reflections on the current approach to antiviral therapy. J Hepatol 2008; 48 (Suppl 1):S2-S19.

8. Chevaliez S, Rodriguez C, Pawlotsky JM. New virologic tools for management of chronic hepatitis B and C. Gastroenterology 2012; 142(6):1303-1313.

9. Wang F, Wang H, Shen H, Meng C, Weng X, Zhang W. Evolution of hepatitis $\mathrm{B}$ virus polymerase mutations in a patient with HBeAg-positive chronic hepatitis B virus treated with sequential monotherapy and add-on nucleoside/nucleotide analogues. Clin Ther 2009; 31(2):360-366.

10. Wu ZP, Han T, Gao YT, Li Y, Liu T, Jing L, et al. Evolution of hepatitis $B$ virus quasispecies during sequential therapy in patients with lamivudine-resistant hepatitis B virus infection. Shijie Hua Ren Xiao Hua Za Zhi (Chin) 2010; 18(8):779-785.

11. Liu L, Tang YZ, Li JG, Zhou JJ, Wang XH, Wang YM. Evolution of hepatitis B virus quasispecies during lamivudine-entecavir sequential therapy. Zhonghua Gan Zang Bing Za Zhi (Chin) 2010; 18(6):423-427.

12. Chen L, Zhang Q, Yu DM, Wan MB, Zhang XX. Early changes of hepatitis $\mathrm{B}$ virus quasispecies during lamivudine treatment and the correlation with antiviral efficacy. J Hepatol 2009; 50(5):895-905.

13. Liu F, Chen L, Yu DM. Evolutionary patterns of hepatitis B virus quasispecies under different selective pressures: correlation with antiviral efficacy. Gut 2011; 60(9):1269-1277. 
14. Lampertico P, Vigano M, Manenti E, Iavarone M, Sablon E, Colombo M. Low resistance to adefovir combined with lamivudine: a 3-year study of 145 lamivudine-resistant hepatitis B patients. Gastroenterology 2007; 133(5):1445-1451.

15. Keeffe EB, Zeuzem S, Koff RS, Dieterich DT, Esteban-Mur R, Gane EJ, et al. Report of an international workshop: roadmap for management of patients receiving oral therapy for chronic hepatitis B. Clin Gastroenterol Hepatol 2007; 5(8):890-897.

16. Chinese Roadmap Expert Group for Telbivudine Treatment. Chinese roadmap for treating chronic hepatitis B with telbivudine. Zhonghua Gan Zang Bing Za Zhi (Chin) 2008; 16(5):323-325.

17. Liaw YF. On-treatment outcome prediction and adjustment during chronic hepatitis B therapy: now and future. Antivir Ther 2009; 14(1):13-22.

18. Lai CL, Gane E, Liaw YF, Hsu CW, Thongsawat S, Wang Y, et al. Telbivudine versus lamivudine in patients with chronic hepatitis B. N Engl J Med 2007; 357(25):2576-2588.

19. Chae HB, Kim MJ, Seo EG. High efficacy of adefovir and entecavir combination therapy in patients with nucleosiderefractory hepatitis B. Korean J Hepatol 2012; 18(1):75-83.

20. Guo XH, Jin R, Zhang SB, Xu B, Zhu RP, Zhang YN, et al. Analysis of the therapeutic effects and drug-resistance of adefovir dipivoxil on patients responded poorly to lamivudine in the management of hepatitis B virus infection. Beijing Yi Xue (Chin) 2011; 33(9):717-720

21. Sun J, Xie Q, Tan DM, et al. Efficacy optimization of response to therapy (EFFORT): a two-year, randomized, open label, controlled study on telbivudine treatment applying the roadmap concept in HBeAg positive chronic hepatitis b (CHB) adult patients: week 76 interim analysis. APASL 2012; PP09-066.

22. Tenney DJ, Rose RE, Baldick CJ, Pokornowski KA, Eggers BJ, Fang J, et al. Long-term monitoring shows hepatitis B virus resistance to entecavir in nucleoside-naïve patients is rare through 5 years of therapy. Hepatology 2009; 49(5):1503-1514.

23. Sheen E, Trinh HN, Nguyen TT, Do ST, Tran P, Nguyen HA, et al. The efficacy of entecavir therapy in chronic hepatitis B patients with suboptimal response to adevofir. Aliment Pharmacol Ther 2011; 34(7):767-774.

24. Pan CQ, Hu KQ, Yu AS, Chen W, Bunchorntavakul C, Reddy KR. Response to tenofovir monotherapy in chronic hepatitis B patients with prior suboptimal response to entecavir. J Viral Hepat 2012; 19(3):213-219.

25. Lok AS, Trinh H, Carosi G, Akarca US, Gadano A, Habersetzer F, et al. Entecavir (ETV) monotherapy for 96 weeks is comparable to combination therapy with ETV plus tenofovir (TDF) in nucleos(t) ide-naive patients with chronic hepatitis B (CHB): the BE-LOW study. 2011. AASLD.

26. Li LJ, Hou JL. Experts proposal on combination therapy of nucleos(t)ide analogues for chronic hepatitis B. Zhonghua Lin Chuang Gan Ran Bing Za Zhi (Chin) 2011; 4(2):65-68.

27. Hou J, Sun J, Xie Q, et al. Virological breakthrough and genotypic resistance in a roadmized, controlled, study on telbivudine treatment applying "roadmap concept" in CHB: W76 interim analysis. 2012. EASL.
28. Piratvisuth T, Komolmit P, Tanwandee T, et al. 1-year results of telbivudine roadmap study demonstrated maximizing antiviral efficacy and minimizing resistance in $\mathrm{HBeAg}$ positive chronic hepatitis B patients. 2011. EASL.

29. Chen EQ, Zhou TY, Bai L, Wang JR, Yan LB, Liang LB, et al. Lamivudine plus adefovir or telbivudine plus adefovir for chronic hepatitis B patients with suboptimal response to adefovir. Antivir Ther 2012; 17(6):973-979.

30. Levrero M, Cimino L, Lampertico P, et al. OptiB - a multicenter prospective open label study on tenofovir for chronic hepatitis B patients with suboptimal response to adefovir or ADV/LAM treatment. 2011. EASL.

31. Chang TT, Gish RG, de Man R, Gadano A, Sollano J, Chao YC, et al. A comparison of entecavir and lamivudine for HBeAg-positive chronic hepatitis B. N Engl J Med 2006; 354(10):1001-1010.

32. Marcellin P, Heathcote EJ, Buti M, Gane E, de Man RA, Krastev $\mathrm{Z}$, et al. Tenofovir disoproxil fumarate versus adefovir dipivoxil for chronic hepatitis B. N Engl J Med 2008; 359(23):2442-2455.

33. Reijnders JG, Perquin MJ, Zhang N, Hansen BE, Janssen HL. Nucleos(t)ide analogues only induce temporary hepatitis B e antigen seroconversion in most patients with chronic hepatitis B. Gastroenterology 2010;139:491-498.

34. van Nunen AB, Hansen BE, Suh DJ, Löhr HF, Chemello L, Fontaine $\mathrm{H}$, et al. Durability of $\mathrm{HBeAg}$ seroconversion following antiviral therapy for chronic hepatitis B: relation to type of therapy and pretreatment serum hepatitis B virus DNA and alanine aminotransferase. Gut 2003; 52(3):420-424.

35. Song BC, Suh DJ, Lee HC, Chung YH, Lee YS. Hepatitis B e antigen seroconversion after lamivudine therapy is not durable in patients with chronic hepatitis B in Korea. Hepatology 2000; $32(4$ Pt 1):803-806.

36. Dienstag JL, Cianciara J, Karayalcin S, Kowdley KV, Willems B, Plisek S, et al. Durability of serologic response after lamivudine treatment of chronic hepatitis B. Hepatology 2003; 37(4):748-755.

37. Yoon SK, Jang JW, Kim CW, Bae SH, Choi JY, Choi SW, et al. Long-term results of lamivudine monotherapy in Korean patients with $\mathrm{HBeAg}$-positive chronic hepatitis B: response and relapse rates, and factors related to durability of $\mathrm{HBeAg}$ seroconversion. Intervirology 2005; 48(6):341-349.

38. Shin JW, Park NH, Park JH, Park JH, Jeong ID, Bang SJ, et al Efficacy of lamivudine re-treatment for relapsed patients after an initial lamivudine therapy in HBeAg-positive chronic hepatitis B. J Viral Hepat 2005; 12(4):393-397.

39. Fung J, Lai CL, Yuen J, Cheng C, Wu R, Wong DK, et al. Randomized trial of lamivudine versus entecavir in entecavirtreated patients with undetectable hepatitis B virus DNA: outcome at 2 Years. Hepatology 2011; 53(4):1148-1153.

40. Wang Z, Wu XL, Zeng WZ, Xu H, Zhang Y, Qin JP, et al. Lamivudine plus adefovir is a good option for chronic hepatitis $B$ patients with viral relapse after cessation of lamivudine treatment. Virol J 2011; 8:388.

41. Wan MB, Weng XH. Consensus on lamvudine optimized therapy on chronic hepatits B. Zhonghua Chuan Ran Bing Za Zhi (Chin) 2012; 30:387-390. 